\title{
Unfolded protein response is involved in the pathology of human congenital hypothyroid goiter and rat non-goitrous congenital hypothyroidism
}

\author{
M Baryshev, E Sargsyan, G Wallin ${ }^{1}$, A Lejnieks ${ }^{2}$, S Furudate ${ }^{3}$, A Hishinuma $^{4}$ and \\ S Mkrtchian \\ Division of Molecular Toxicology, Institute of Environmental Medicine, Karolinska Institutet, Nobels väg 13 , 17177 Stockholm, Sweden \\ 1Department of Surgery, Karolinska Hospital, 17176 Stockholm, Sweden \\ 2Stradinja University, Riga, Latvia \\ ${ }^{3}$ Department of Laboratory Animal Science, Kitasato University School of Medicine, Sagamihara-shi, Kanagawa 228-8555, Japan \\ ${ }^{4}$ Department of Clinical Laboratory Medicine, Dokkyo University School of Medicine, Mibu, Tochigi 321-0293, Japan \\ (Requests for offprints should be addressed to S Mkrtchian; Email: souren.mkrtchian@imm.ki.se) \\ (M Baryshev and E Sargsyan contributed equally to this work)
}

\begin{abstract}
The unfolded protein response (UPR) is an intracellular signaling pathway that regulates the protein folding and processing capacity of the endoplasmic reticulum (ER). The UPR is induced by the pharmacological agents that perturb ER functions but is also activated upon excessive accumulation of the mutant secretory proteins that are unable to attain correct three-dimensional structure and are thus retained in the ER. Such defects in intracellular protein transport underlie the development of a number of phenotypically diverse inherited pathologies, termed endoplasmic reticulum storage diseases (ERSD). We have studied UPR development in two similar ERSDs, human congenital goiter caused by the C1264R and C1996S mutations in the thyroglobulin $(\mathrm{Tg})$ gene and non-goitrous congenital hypothyroidism in $r d w$ dwarf rats determined by the G2320R Tg mutation. In both cases, these mutations rendered $\mathrm{Tg}$ incapable of leaving the ER. A major ER chaperone immunoglobulin-binding protein (BiP), and a novel putative escort chaperone endoplasmic reticulum protein $29 \mathrm{KDa}$ (ERp29) were found to be associated with $\mathrm{Tg}$, which might be interpreted as the contribution of the quality control machinery to the previously shown retention of $\mathrm{Tg}$ in the ER. We have extended our earlier observations of ER chaperone induction with the identification of the additional ER (ERp29, ERp72, calreticulin, protein disulfide isomerase (PDI)), cytoplasmic (heat shock protein (HSP)70, HSP90) and mitochondrial (mtHSP70) upregulated chaperones and folding enzymes. Activation of the transcriptional arm of UPR, as judged by the appearance of the spliced (active) form of X-box binding protein (XBP1) and processed activating transcription factor 6 (ATF6) transcription factors was suggested to contribute to the overexpression of the ER chaperones. The processing of ATF6 was observed in both human and rat tissues with Tg mutations. Whereas, in human tissues, weak splicing of XBP1 mRNA was detected only in the C1264R mutant, all rat thyroids including wild-type contained significant amounts of the spliced form of XBP1 as opposed to human liver and rat brain tissues, implying the existence of a previously unknown tissue-specific regulation of XBP1 processing.
\end{abstract}

Journal of Molecular Endocrinology (2004) 32, 903-920

\section{Introduction}

The unfolded protein response (UPR) is an adaptive cellular reaction that maintains the homeostasis of the endoplasmic reticulum (ER) perturbed by the accumulation of unfolded or misfolded proteins (Mori 2000, Harding et al. 2002, Kaufman 2002). Such protein species amass in the ER under the conditions of environmental stress and also when the folding capacity of the ER 
becomes insufficient for the massive amounts of newly synthesized secretory or membrane proteins (physiological stress). Mammalian UPR consists of two arms, transcriptional induction of the genes that enhance the ER-folding capacity (molecular chaperones, folding enzymes) and general translational attenuation aimed at the reduction of the protein load on the ER. UPR is activated through the co-ordinated action of the ER membrane-bound proximal UPR sensors, ATF6, inositol requiring-1 (IRE1) (transcriptional arm) and PERKR-like endoplasmic reticulum kinase (PERK) (translational arm). In unstressed cells, these sensors are silenced by interaction with a major $\mathrm{ER}$ chaperone, $\mathrm{BiP}$ (Bertolotti et al. 2000, Shen et al. 2002). ER overload initiates dissociation of $\mathrm{BiP}$ from the luminal domains of the sensor molecules in order to maintain certain levels of free BiP, thus activating ATF6, IRE1 and PERK. Ninety kDa ATF6 (p90 ATF6) migrates to Golgi apparatus where it is cleaved by site 1 and site 2 proteases to produce an active, $\sim 50 \mathrm{kDa}$ basic leucine zipper (bZIP) transcription factor (p50ATF6) (Haze et al. 1999, 2001) that transactivates the ER stress response elements of the major UPR target genes, ER molecular chaperones (Yoshida et al. 1998). Transmembrane kinases IRE1 and PERK are activated via dimerization of their luminal domains and autophosphorylation (Tirasophon et al. 1998, Wang et al. 1998, Bertolotti et al. 2000). Subsequently, IRE1 triggers formation of the active form of another bZIP transcription factor, XBP1 by the unusual mechanism of 'frame shift splicing' (Yoshida et al. 2003). In response to the ER stress, XBP1 mRNA is spliced by the activated endonuclease domain of IRE1 producing a new open reading frame where the bZIP domain is joined with the new C-terminal transactivation domain (Yoshida et al. 2001, Calfon et al. 2002, Lee et al. 2002, Shen et al. 2001). XBP1 has more pleiotropic effects and along with upregulation of immediate rescue genes (chaperones) (Yoshida et al. 2001) appears to induce transcription of other, as yet poorly characterized UPR targets (Nyfeler et al. 2003, Yoshida et al. 2003). Activation of another transmembrane kinase, PERK, provides an efficient translation control on the early stages of UPR via phosphorylation/inhibition of eukaryotic initiation factor 2- $\alpha$ (eIF2- $\alpha$ ) translation initiation factor (Harding et al. 1999).

In addition to the environmental stressors and physiological protein overload, UPR is initiated by the excessive accumulation of the mutant secretory proteins due to their failure to acquire correct conformation and couple to the export machinery. A group of phenotypically diverse inherited pathologies, termed endoplasmic reticulum storage diseases (ERSD), with a similar molecular pathogenesis, includes such disorders as cystic fibrosis, neurodegenerative diseases and others (for detailed reviews see Kim et al. 1998a, Aridor \& Balch 1999, Rutishauser \& Spiess 2002). Disease pathology may be triggered by the cytotoxic effects of the protein overload or simply by the lack of the functional protein in the target organelle or cell exterior. Transport-incompetent cargo molecules are typically eliminated in the ER-associated degradative pathway (ERAD), which is also considered to be an integral part of the UPR (Plemper \& Wolf 1999, Hampton 2002). In more severe cases, defective proteins fail to degrade and form large aggregates in the ER. A number of hereditary endocrinopathies, including congenital hypothyroid goiter, were suggested to develop according to such a molecular scenario (Kim et al. 1998a). The defects in the thyroglobulin $(\mathrm{Tg})$ gene were reported to be responsible for the disease pathology in some cases of congenital hypothyroidism (Kim et al. 1998a). Analysis of several $\mathrm{Tg}$ mutations in patients with congenital hypothyroid syndrome demonstrated that, at least in some of them, defective $\mathrm{Tg}$ molecules were unable to leave the ER and thus this pathology may be classified as ERSD. Medeiros-Neto et al. (1996) examined two independent kindreds with a congenital goiter and found that, despite apparently normal synthesis and glycosylation, $\mathrm{Tg}$ failed to reach the thyroid follicular lumen. However, the genetic basis of such defects in the folding/assembly of $\mathrm{Tg}$, at least in one kindred, was not identified. A detailed study of two unrelated patients with a congenital goiter and two siblings with a variant type of adenomatous goiter revealed replacement of two conserved cysteines by arginine (G1264R) and serine (C1996S), which resulted in the retention and aggregation of Tg in the ER (Hishinuma et al. 1998, 1999). Additionally, two rodent models that have provided important insights into the molecular and cellular mechanisms associated with abnormal $\mathrm{Tg}$ trafficking have been described. In recessive $\operatorname{cog} / \operatorname{cog}$ mice with a congenital hypothyroid goiter, missense mutation in the acetylcholinesterase domain of $\mathrm{Tg}$ disrupts the tertiary structure of $\mathrm{Tg}$ which fails to 
homodimerize and travel to Golgi (Kim et al. 1998b). In contrast to $\operatorname{cog} / \operatorname{cog}$ mice and human patients, rdw dwarf rats do not develop goiters. However, mutation of the conserved glycine (G2320R) leads to the same molecular and phenotypic consequences: severe defect in $\mathrm{Tg}$ export with retention in the ER and a typical hypothyroid syndrome (Hishinuma et al. 2000, Kim et al. 2000).

In all of the above-described studies, retention of $\mathrm{Tg}$ was accompanied by increased expression of the major ER chaperones, BiP and glucose regulated protein $94 \mathrm{KDa}$ (GRP94), important components of the ER quality control machinery which prevents the export of incompletely folded proteins from the ER. Simultaneously, chaperone induction apparently signals the initiation of the UPR. In several recessive inherited genetic diseases, it has been suggested that UPR contributes to disease progression (Kim et al. 1998a), which prompted our interest towards a more detailed study of the UPR in the congenital hypothyroid disorders connected with the folding/secretion defects of $\mathrm{Tg}$.

We have chosen previously characterized cases of human congenital hypothyroid goiter caused by different mutations in $\mathrm{Tg}$ and a rodent model of congenital hypothyroidism in $r d w$ rats. Although phenotypically very different ( $r d w$ rats do not develop goiter), molecular pathogenesis in both cases has a common denominator: inability of defective mutant $\mathrm{Tg}$ to leave the $\mathrm{ER}$ with the ensuing development of the unfolded protein response.

\section{Materials and methods}

\section{Human subjects and tissue treatment}

Patient M1 had a congenital euthyroid goiter. Patient M2 had a variant type of adenomatous goiter (Hishinuma et al. 1999). Thyroid tissues were also obtained from two patients with the diagnoses of follicular adenoma and Hashimoto's thyroiditis and, additionally, from the clinically and morphologically normal left lobe of a patient suffering from a papillary thyroid carcinoma in the right lobe, which is further referred to as the normal sample. Human tissues were obtained from the patients following the rules and with the approval of the University Hospital Ethical Committees of
Dokkyo University School of Medicine, Stradinja University and the Karolinska Hospital. Informed consent was obtained from all the patients involved in the study.

Tissue samples were immediately frozen in liquid nitrogen and kept at $-80{ }^{\circ} \mathrm{C}$. Tissue extracts were prepared by homogenization of $20 \mathrm{mg}$ thyroid gland in $100 \mu \mathrm{l}$ Tris-HCl buffer (pH 8.0) containing 'Complete' protease inhibitors cocktail (Roche, Basle, Switzerland) using a Dounce homogenizer. Homogenates were centrifuged for $30 \mathrm{~min}$ twice at $18000 \boldsymbol{g}$ and the final supernatant was used for further analyses. Protein concentration in the tissue extracts was measured by the method of Lowry et al. (1952).

\section{Animals and tissue treatment}

$r d w$ rats were derived from the Wistar-Imamichi strain as described elsewhere (Koto et al. 1988). The animals were maintained at the laboratory animal facility of Kitasato University School of Medicine. The genotype of wild-type $(+/+)$, heterozygous $(+/ r d w)$ and homozygous $(r d w / r d w)$ rats was confirmed by genomic DNA analysis (Hishinuma et al. 2000). Male rats were killed at 15-18 weeks of age by decapitation under ether anesthesia and the thyroids were removed, frozen and kept at $-80{ }^{\circ} \mathrm{C}$ until use. Animal use procedures were in accordance with the guidelines for the care and use of laboratory animals of Kitasato University School of Medicine. Tissue extracts were prepared as described above.

\section{SDS-PAGE and Western blot}

Tissue extracts were analyzed by reducing SDSPAGE followed by either Coomassie blue staining or Western blot. For immunoblotting, proteins were transferred to the nitrocellulose membranes and probed by antibodies against endoplasmic reticulum protein $29 \mathrm{KDa}$ (ERp29) (rabbit polyclonal anti-rat ERp29 antibody (Ab) or mouse monoclonal anti-ERp29), $\mathrm{Tg}$ (polyclonal anti-rat Ab from Dr B Di Jeso, University of Lecce, Italy; polyclonal or mouse monoclonal anti-human $\mathrm{Ab}$ from DAKO, Glostrup, Denmark), BiP (polyclonal anti-mouse $\mathrm{BiP} \mathrm{Ab}$ provided by Drs L Hendershot and L Meunier, St Jude Children's Research Hospital, Memphis, TN, USA; rabbit polyclonal 
anti-KDEL Ab from StressGen, Victoria, Canada), GRP94 (mouse monoclonal anti-GRP94 Ab, a gift from Dr L Gorza, GNR Institute of Neuroscience, Padua, Italy), protein disulfide isomerase (PDI) (mouse monoclonal anti-PDI Ab from Affinity BioReagents, Colorado, USA), calreticulin (rabbit polyclonal anti-calreticulin $\mathrm{Ab}$ from Affinity Bioreagents), endoplasmic reticulum protein $72 \mathrm{KDa}$ (ERp72) (provided by Dr J G Higuita, MTG, Karolinska Institute, Stockholm, Sweden), mitochondrial heat shock protein (HSP)70 (mtHSP70) (mouse monoclonal anti-mtHSP70 Ab from Affinity BioReagents), HSP70 (mouse monoclonal anti-HSP70 Ab from Affinity BioReagents), HSP90 (rabbit polyclonal anti-HSP90 Ab from Santa Cruz Biotechnology, Santa Cruz, CA, USA) and actin (goat polyclonal anti-actin Ab from Santa Cruz). ATF6 (polyclonal anti-human ATF6 $\alpha$ Ab) and XBP1 (rabbit polyclonal Ab against the N-terminal 74 amino acid fragment of human XBP1; Abs were generously provided by Dr K Mori, Kyoto University, Kyoto, Japan). Immunoreactive bands were visualized by the SuperSignal enhanced chemiluminescence kit according to the manufacturer's specifications (Pierce, Rockford, IL, USA) using the luminescent image analysis system LAS $1000+$ (Fujifilm, Fujifilm Sverige AB, Stockholm, Sweden).

\section{Immunoprecipitations}

Immunoprecipitations were carried out with the polyclonal anti-ERp29 immunoglobulins (IgGs) conjugated with GNBr-activated Sepharose (Amersham Pharmacia Biotech Sverige, Uppsala, Sweden), polyclonal anti-human Tg Ab (DAKO) or polyclonal anti-rat $\mathrm{Tg} \mathrm{Ab}$ (from Dr B Di Jeso) for 1-3 h. All samples were precleared for $1 \mathrm{~h}$ with 25\% Protein A-Sepharose beads (Amersham Pharmacia Biotech Sverige) and preimmune rabbit serum. The supernatant was used for further immunoprecipitations after brief centrifugation. Protein A-Sepharose was added to the samples precipitated with anti-Tg $\mathrm{Ab}$ and incubated for $1 \mathrm{~h}$. Immunocomplexes were washed three times with phosphate-buffered saline (PBS) containing 1\% Triton X-100, once in PBS and water, and eluted by the SDS-PAGE sample buffer with subsequent reducing SDS-PAGE. Proteins from the gel were transferred to the nitrocellulose membrane and analyzed by immunoblotting.

\section{XBP1 mRNA splicing}

Total RNA from human and rat tissues was isolated using the standard acid phenol/guanidine isothiocyanate procedure (Chomczynski \& Sacchi 1987) and reverse transcribed using M-MLV reverse transcription kit (Invitrogen, Carlsbad, CA, USA). A 479 bp fragment of human XBP1 cDNA and a $485 \mathrm{bp}$ fragment of the rat hepatocarcinogenesis-related transcription factor (HTF) (XBP1) encompassing 26 bp introns were amplified with forward (AGAGTAGCAGCTCAGACTG CGAG (human), AGAGTAGGAGCTCAGACT GCGAG (rat)) and reverse (GGAACTGGGTG CTTCTGGGTA) primers and PGR products were digested by Pst $\mathrm{I}$ restriction enzyme for $16 \mathrm{~h}$. The digestion mixture was run on $2 \%$ agarose gels and DNA fragments were detected by the fluorescent image analysis system LAS 1000+ (Fujifilm). Treatment of rat epithelial thyroid cells (FRTL-5) for $12 \mathrm{~h}$ with $10 \mu \mathrm{g} / \mathrm{ml}$ tunicamycin (Sigma, St Louis, MO, USA) with further isolation of RNA, RT-PGR and PstI digestion was used as a positive control for the XBPl (HTF) splicing event.

\section{Results}

\section{Chaperone induction in affected human subjects and $r d w / r d w$ rats}

Human thyroid tissues used in this study were obtained from two patients whose clinical status, phenotype and $\mathrm{Tg}$ cDNA sequence have been described in detail previously (Hishinuma et al. 1999). Thyroid function tests revealed mild hypothyroidism to euthyroidism. Most of the basic thyroid parameters were approximately similar in both patients; however, serum $\mathrm{Tg}$ content was lower than the normal range in patient $\mathrm{M} 1$ carrying the G1264R Tg mutation and substantially higher in patient M2 with a variant type of adenomatous goiter carrying the C1996S mutation (see Table 2 in Hishinuma et al. 1999). At the same time, tissue $\mathrm{Tg}$ content in both subjects was drastically lower, as compared with normal tissues. The total protein profile in the thyroid tissue extracts of these patients was analyzed and compared with the tissue samples obtained from patients with unrelated pathologies where $\mathrm{Tg}$ secretion was unaltered. Similar results were demonstrated in our previous report (Hishinuma et al. 1999). As shown in Fig. 1, all control thyroids 


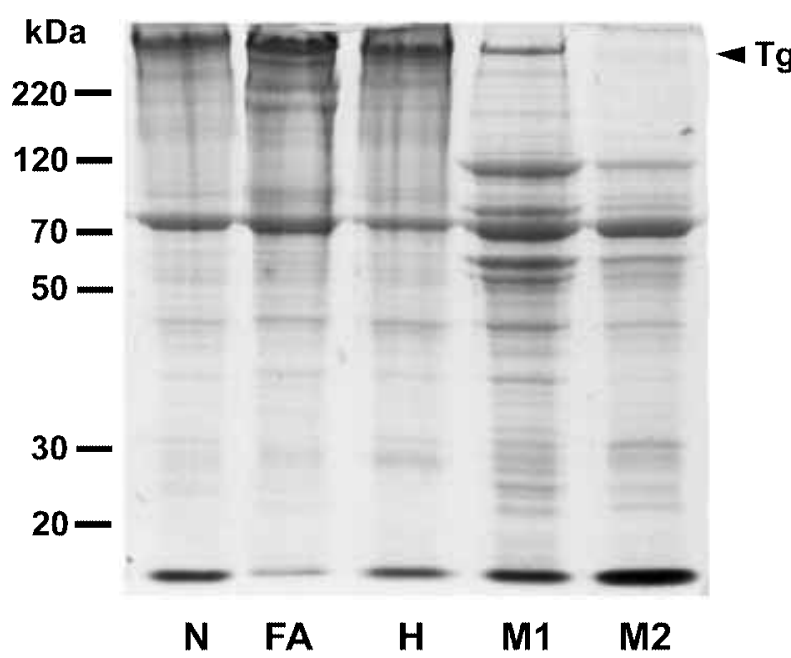

Figure 1 Altered protein profile in the mutant human thyroid tissues. Thyroid homogenates from affected patients and three individuals with unrelated pathologies were normalized by protein and analyzed by reducing 8.5\% SDS-PAGE and Coomassie staining. N, thyroid tissue from the normal thyroid lobe (see Materials and methods), FA, follicular adenoma, H, Hashimoto's thyroiditis, M1, patient with a congenital hypothyroid goiter and C1264R Tg mutation and M2, patient with a variant type of adenomatous goiter and C1996S Tg mutation.

contained approximately similar amounts of $\mathrm{Tg}$, whereas patients with $\mathrm{Tg}$ mutations exhibited a drastic decrease in $\mathrm{Tg}$ levels, in particular, in patient M2. Immunoblotting (results not shown) confirmed the authenticity of the $\mathrm{Tg}$ band and, moreover, immunoreactive $\mathrm{Tg}$ was detected even in the thyroid tissue of patient M2, despite the absence of the Coomassie-stained band, which would probably reflect the low sensitivity of the gel staining. The correct size of the M1 and M2 Tg bands implicitly confirms the correct mRNA translation and post-translational modifications of $\mathrm{Tg}$ in these patients. Interestingly, in parallel with the reduced quantities of $\mathrm{Tg}$, a number of protein bands in the region of $\sim 30, \sim 55, \sim 75$ and $\sim 90 \mathrm{kDa}$ were selectively increased in the affected patients (Fig. 1).

When the tissue extracts were examined by Western blot, these bands were identified as major ER chaperones, BiP (78 kDa), GRP94 (94 kDa) and an ER-folding enzyme PDI $(58 \mathrm{kDa})$ that are commonly induced under ER stress (Fig. 2A). Probing with $\mathrm{Tg}$ antibodies failed to reveal any immunoreactivity in these regions, which argues against the existence of proteolytic fragments of $\mathrm{Tg}$, at least of the sizes indicated (results not shown). Additionally, other ER chaperones, such as calreticulin $(60 \mathrm{kDa})$, the recently discovered putative Tg escort chaperone, ERp29 (29 kDa) and the PDI-like folding enzyme, ERp72 (72 kDa) were also elevated in M1 and M2 tissues. The pattern of these changes was nearly similar and M1 tissue extract typically exhibited higher expression levels of all the proteins examined. GRP94 showed the strongest induction, being upregulated $80-$ and 56 -fold (after normalization by $\beta$-actin) in $\mathrm{M} 1$ and M2 respectively (Fig. 2B). BiP demonstrated similar expression levels (69- and 40-fold increase). To our surprise, even cytosolic (HSP70, HSP90) chaperones were substantially induced, although not to the same levels as their ER counterparts BiP and GRP94 (Fig. 2B). Similar upregulation was demonstrated by the mitochondrial paralogue of HSP70 (mtHSP70) with an unexpectedly strong increase in the thyroid extract from the patient with Hashimoto's thyroiditis (Fig. 2). Taken together, these data demonstrated that the cellular adaptive response to the impaired intracellular $\mathrm{Tg}$ transport in these patients is not confined only to the ER but apparently includes also cytoplasmic and mitochondrial reorganization.

\section{Interaction of $\mathrm{Tg}$ with ER chaperones in the thyroids of affected patients}

Progression of the secretory proteins through the secretory pathway is monitored by the quality control mechanisms that include identification of misfolded species and extended interaction with molecular chaperones preventing the export of incorrectly folded proteins. In order to establish the roles of individual ER chaperones in the processing of mutant $\mathrm{Tg}$, we have employed a coimmunoprecipitation assay with further immunoblotting to determine proteins associated with $\mathrm{Tg}$. Immune complexes from the human thyroid tissues precipitated by $\mathrm{Tg}$ antibodies were tested for several proteins previously shown to interact with Tg: BiP, GRP94 and ERp29 (Kuznetsov et al. 1994, Muresan \& Arvan 1997, Sargsyan et al. 2002). Despite the known problems with the integrity of non-covalent protein complexes in frozen/thawed samples, BiP was readily detected in $\mathrm{Tg}$ immunoprecipitates from the M1 and M2 


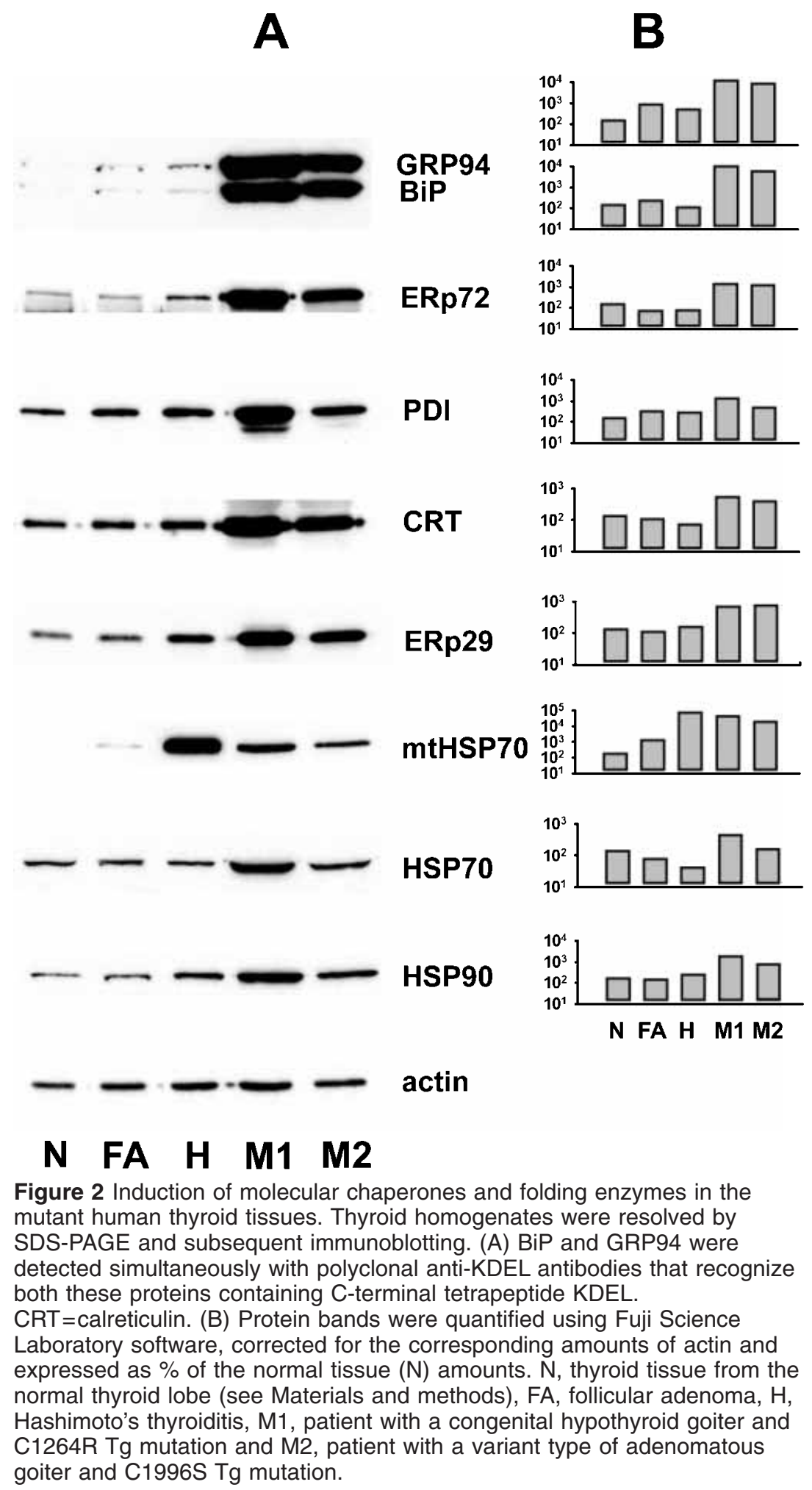


A

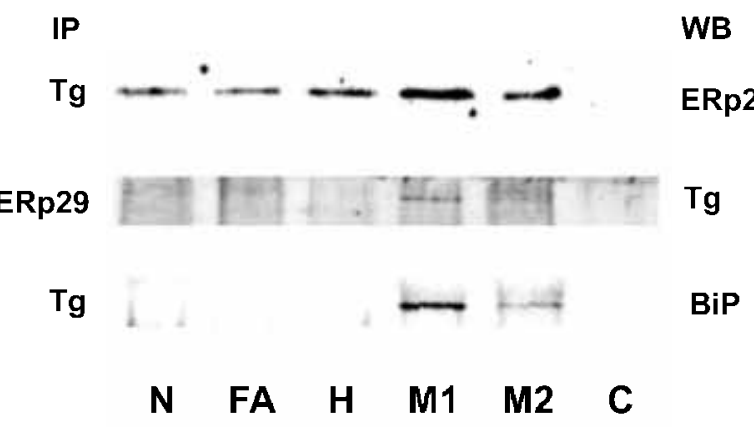

B
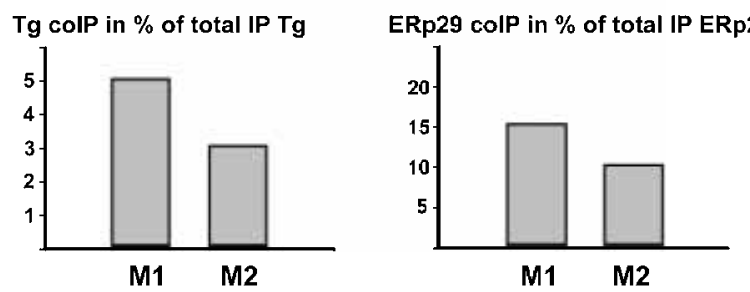

Figure 3 Association of ERp29 and BiP with $\mathrm{Tg}$ in the mutant human thyroid tissues. Thyroid homogenates representing equal amounts of protein were immunoprecipitated (IP) with BrCN-immobilized ERp29 polyclonal IgGs, polyclonal anti-human Tg or control rabbit serum (C). (A) Proteins were resolved by SDS-PAGE and analyzed by Western blot (WB). (B) The extent of the ERp29 association with $\mathrm{Tg}$ in affected patients was quantified by relating the amount of ERp29 co-immunoprecipitated by anti-Tg to the total amount of ERp29 immunoprecipitated by anti-ERp29. Tg and ERp29 immunoprecipitates from M1 and M2 samples were run on the same gel and probed with the monoclonal anti-ERp29 (results not shown). An identical procedure was carried out for the quantification of $\mathrm{Tg}$ association with ERp29 in the ERp29 immunoprecipitates using monoclonal anti-Tg. Results are expressed in \% of total immunoprecipitated Tg (left panel) or ERp29 (right panel). colP, co-immunoprecipitation $\mathrm{N}$, thyroid tissue from the normal thyroid lobe (see Materials and methods), FA, follicular adenoma, $\mathrm{H}$, Hashimoto's thyroiditis, M1, patient with a congenital hypothyroid goiter and C1264R Tg mutation and M2, patient with a variant type of adenomatous goiter and C1996S Tg mutation.

tissues and, moreover, its amounts were substantially higher in patient M1, apparently reflecting the difference in the induction levels noted previously (Fig. 3A). BiP was not identified in the other human tissues tested, which may be explained either by the low levels of $\mathrm{Tg} / \mathrm{BiP}$ complexes that easily dissociate upon thawing, or by the known trait of $\mathrm{BiP}$ to bind only to misfolded polypeptides (Gething 1999). As previously established, GRP94 can be coimmunoprecipitated with $\mathrm{Tg}$ only if chemical cross-linking is utilized (Muresan \& Arvan 1997, Sargsyan et al. 2002). However, we were not able to detect GRP94 even in cross-linked samples (data not shown), which might be caused by the specifics of the frozen/thawed tissue immunoprecipitations, and/or to a lesser extent of Tg/GRP94 interaction as compared with BiP. In contrary to GRP94, ERp29 was found not only in the mutant Tg tissues with a preferential accumulation in the M1 sample, but also in normal thyroid, follicular adenoma and Hashimoto's thyroiditis (Fig. 3A). This correlated perfectly with our previous data (Sargsyan et al. 2002) where ERp29 was demonstrated to interact not only with unfolded and, to a lesser extent, also with a normal Tg. ERp29/Tg association was also confirmed by reverse co-immunoprecipitation (Fig. 3A) where the quantitative evaluation indicated that in mutant thyroids a significant fraction $(\sim 10-20 \%)$ of total immunoprecipitated ERp29 is associated with Tg (Fig. 3B, right panel). Surprisingly, the quantification of the reverse co-immunoprecipitations revealed substantially weaker association levels (Fig. 3B, left panel), which might apparently be explained by the lower efficiency of anti-rat ERp29 in immunoprecipitating human ERp29 and all interacting proteins (Tg) respectively.

\section{Induction of ER chaperones in rdw/rdw rats}

The total protein pattern in $r d w$ rat thyroids has been studied by SDS-PAGE and Coomassie staining (Fig. 4). Our results basically confirm and extend previous observations of the altered protein profile and chaperone expression in mutant rats (Hishinuma et al. 2000, Kim et al. 2000). The wild-type $(+/+)$, hetero- $(+/ r d w)$ and homozygote $(r d w / r d w)$ rats expressed $\mathrm{Tg}$ of identical size (confirmed by immunoblotting, results not shown) however, the amounts of $\mathrm{Tg}$ differed substantially. In heterozygote rats, $\mathrm{Tg}$ is already slightly reduced, whereas $r d w / r d w$ rats, similarly to hypothyroid human patients, exhibited merely traces of $\mathrm{Tg}$. Again, a number of protein bands in the $\sim 30-100 \mathrm{kDa}$ range were upregulated in the $+/ r d w$ and $r d w / r d w$ rats. Western blot analysis identified at least some of them as ERp29, PDI, calreticulin, ERp72, BiP and GRP94 (Fig. 5A). As 


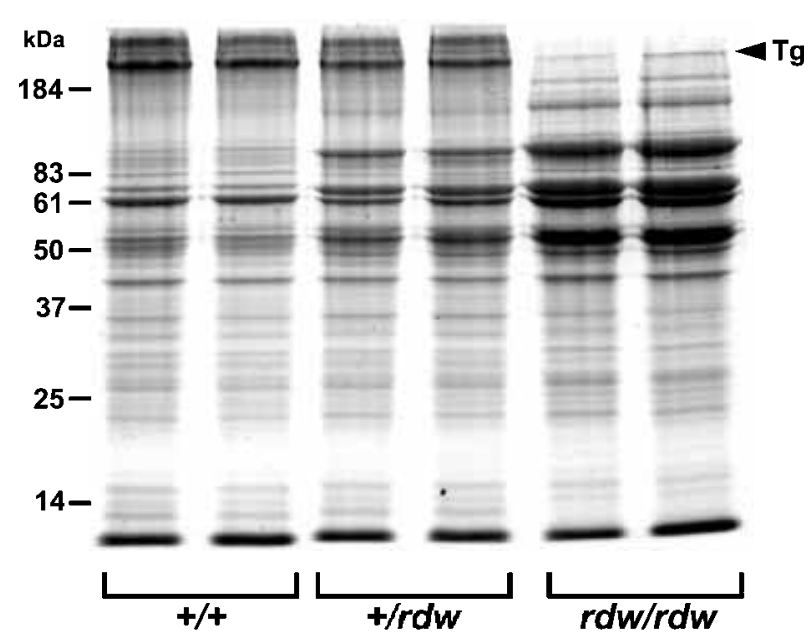

Figure 4 Total protein profile of the $r d w$ rat thyroids. Thyroid protein extracts were analyzed by reducing 8.5\% SDS-PAGE and Coomassie staining. +/+, wild-type Wistar-Imamichi rats, $+/ r d w$, heterozygote rats, $r d w / r d w$ homozygote rats. Thyroids from two animals were used in each experimental group.

in the human tissues, the elevation of GRP94 and BiP levels was more pronounced (6- and 8-fold respectively in homozygote rats), as compared with other chaperones and folding enzymes (Fig. 5B). Cytosolic chaperones represented by HSP90 remained unaltered (previous reports, however, indicated upregulation of HSP70 (Oh-Ishi et al. 1998)), but mitochondrial HSP70 was increased, although not as drastically as in human tissues.

\section{BiP and ERp29 associate with Tg in rdw/rdw rats}

Immunoprecipitation of $\mathrm{Tg}$ and probing of the immune complexes with anti-BiP and ERp29 revealed association of these proteins with $\mathrm{Tg}$, which was further confirmed by reverse immunoprecipitation (Fig. 6A). GRP94, which has been suggested to be one of the essential quality control factors for $\mathrm{Tg}$, could not been detected in the $\mathrm{Tg}$ immunoprecipitates even upon cross-linking (results not shown) apparently because of the same reasons as in the case of human tissues. ERp29 detection already in wild-type rat $\mathrm{Tg}$ immune complexes, similarly to human subjects, supports its putative role as an escort chaperone that may retain association with $\mathrm{Tg}$ even after it completes its folding. Finally, the quantitative evaluation of ERp29/Tg complexes, similarly to human tissues, demonstrated that in the thyroids of heteroand homozygote animals sizable fractions of ERp29 were present in the Tg-immune complexes (Fig. 6B, left panel) and vice versa (right panel). The effects were clearly dependent on the number of defective alleles being more pronounced in the $r d w / r d w$ rats.

\section{ATF6 and XBP1 activation in human and rat thyroid tissues}

Previous studies and our current data implicitly indicate common mechanisms underlying chaperone-induction phenomena in human congenital goiter and rdw mutant rats. Compensatory increase of ER chaperones under ER stress and physiological overload is believed to be regulated by two bZIP transcription factors ATF6 and XBP1 (see Introduction). We have attempted to study the possible causative link between the chaperone elevation in thyroid disorders and the activation of these key UPR transducers. ATF6 antibodies raised against the $\alpha$ isoform of the protein were used for immunoblotting of both human and rat tissues (Haze et al. 1999). The inactive form of ATF6, $\sim 90 \mathrm{kDa}$ protein, was readily detected in all tissues tested (Fig. 7A). The appearance of the protein band of the predicted size $(\sim 50 \mathrm{kDa})$ in the $\mathrm{Ml}$ and M2 patients unambiguously indicated an active UPR. As was shown already by chaperone induction studies (Fig. 2), the intensity of the UPR is incomparably stronger in Ml tissue as judged by the amount of the nuclear form of ATF6. The origin of the additional bands in the Ml sample is currently unknown, although their proteolytic nature cannot be ruled out. Interestingly, the homozygote $r d w / r d w$ rat displayed increased amounts of p90 ATF6, although the transcriptional mechanisms of such induction remain obscure (Fig. 8A). Homozygote $r d w$ rat thyroids also featured the processed fragment of ATF6 of a slightly different molecular weight $(\sim 62 \mathrm{kDa})$ which might be dependent on the specific properties of rat ATF6 or simply on the aberrant electrophoretic migration (Fig. 8A). ATF6 $\beta$ has a slightly higher molecular weight; however, the antibodies used in these study were not reported to cross-react with the $\beta$ isoform (Haze et al. 1999).

Activation of the other important transcriptional regulator of UPR, XBP1, was first examined using antibodies raised against the $\mathrm{N}$-terminal 74 amino 


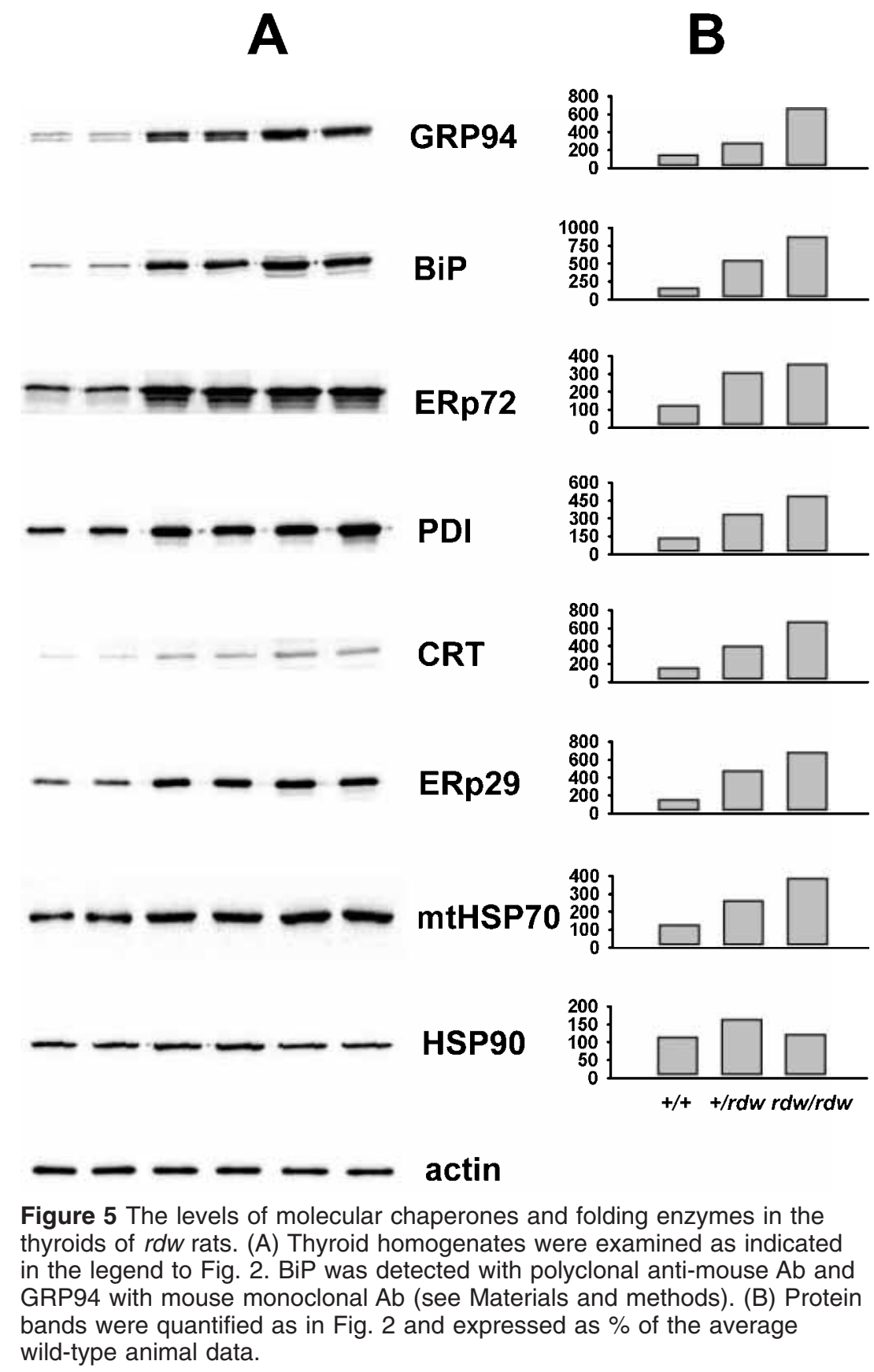

acid fragment of the protein that can recognize both spliced (active) and unspliced forms of the protein (Yoshida et al. 2001). However, despite the weak appearance in mutant samples of the band with a correct molecular weight $(\sim 54 \mathrm{kDa})$ of the spliced XBP1 (results not shown), the immunoblots were not clear enough because of the strong nonspecific immunostaining in the region of interest. We therefore chose to study the activation of the IRE1/XBP1 system by monitoring the splicing of the $26 \mathrm{bp}$ fragment (intron) from the XBP1 mRNA. This reaction is catalyzed by the active IRE1 and results in the reading frame shift and translation of the transcriptionally active XBP1 protein. The $26 \mathrm{bp}$ intron present in the unspliced mRNA contains a unique PstI recognition site. 
A

IP

$\mathrm{Tg}$
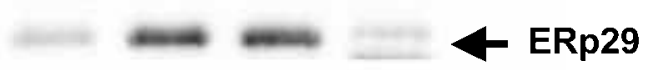

ERp29

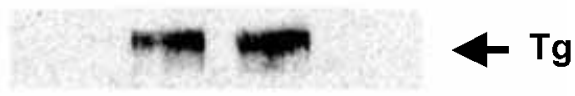

$\mathrm{Tg}$

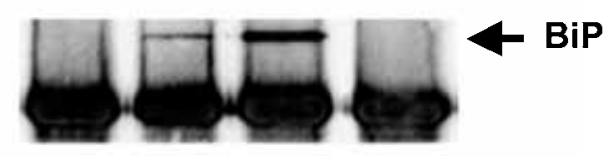

ERp29

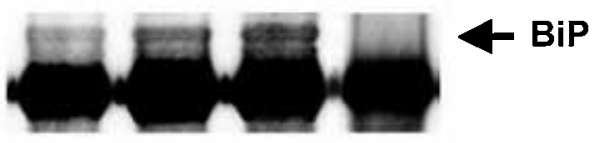

$+/+\quad+/ r d w \quad r d w / r d w \quad$ C

\section{B}

Tg colP in \% of total IP Tg

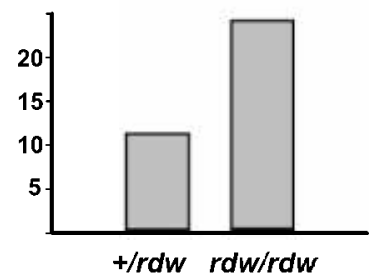

ERp29 colP in \% of total IP ERp29

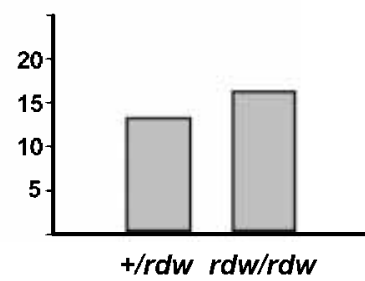

Figure 6 Association of ERp29 and BiP with Tg in the $r d w$ thyroids. Thyroid homogenates from two animals in each group were pooled and equal amounts of protein were immunoprecipitated (IP) with $\mathrm{BrCN}$-immobilized ERp29 polyclonal IgGs, polyclonal anti-rat Tg, anti-mouse BiP or control rabbit serum (C). (A) Proteins were resolved by SDS-PAGE and analyzed by Western blot (WB). Additional bands in the tissue samples immunoprecipitated by anti-Tg and ERp29 and probed by anti-BiP represent heavy chains of immunoprecipitating antibodies ( $50 \mathrm{kDa})$. (B) ERp29 association with $\mathrm{Tg}$ was evaluated quantitatively as described in the legend to Fig. 3B. colP, co-immunoprecipitation.

Digestion of the $\sim 500$ bp PGR fragment of the $\mathrm{XBP} 1$ cDNA encompassing the restriction site was used to discriminate between spliced (Pst I-resistant) and unspliced (Pst $\mathrm{I}$-sensitive) forms of XBP1.
Most of the human samples tested were found to contain only the unspliced form of XBP1 (Fig. 7B, upper panel), migrating at the same level as the upper band of the PCR product amplified from the cDNA of FRTL-5 thyroid cells treated with tunicamycin, a known activator of UPR (Fig. 8B, lane Tun). However, the M1 tissue displayed a faint but distinct band identical to the lower (spliced) fragment of the tunicamycin-treated positive control. The difference in migration corresponds approximately to the size of the excised intron (26 bp). Not surprisingly, Pst $\mathrm{I}$ treatment caused nearly complete digestion of the PCR products from all tissues with the ensuing 281 and $198 \mathrm{bp}$ fragments (Fig. 7B, lower panel). The PstI-resistant, spliced form is more clearly visible in the M1 lane because of the partial digestion of the higher migrating unspliced product 'shielding' the spliced band in the undigested sample.

Application of the same method for the detection of XBP1 mRNA processing to the $r d w$ rat tissues, despite certain differences from the human results, implicitly confirmed activation of the IRE1/XBP1 pathway in the thyroids producing mutant $\mathrm{Tg}$. Interestingly, all of the studied samples contained both spliced and unspliced forms of HTF (XBP1) mRNA (Fig. 8B, upper panel), as opposed to the absence of such a band in the control rat brain sample (Fig. 8B lane B). The digestion of these amplicons demonstrated relative enrichment of the PstI-resistant (spliced) fragment in the heterozygous and homozygous animals and lower amounts of the digestion products similar to the human M1 sample (Fig. 7B). However, more precise estimations here were hindered by the quasi-quantitative nature of the PCR assay. It is noteworthy that, even after exhaustive digestion, significant amounts of the slower migrating fragment (unspliced) were observed in rat as well as human tissues (Figs 7B and $8 \mathrm{~B}$, lower panels). The instances of such an obscure PstI-refractory 'unspliced' form were reported previously (Kumar et al. 2003). Relatively high quantities of such undigested material were seen in the $r d w / r d w$ and M1 samples that represent tissues with the highest levels of UPR, as judged by the chaperone expression and ATF6 processing. Our attempt to purify and sequence these DNA fragments showed significant enrichment with the spliced XBP1 (results not shown). However, the reason for such aberrant migration of the spliced form remains unclear. 

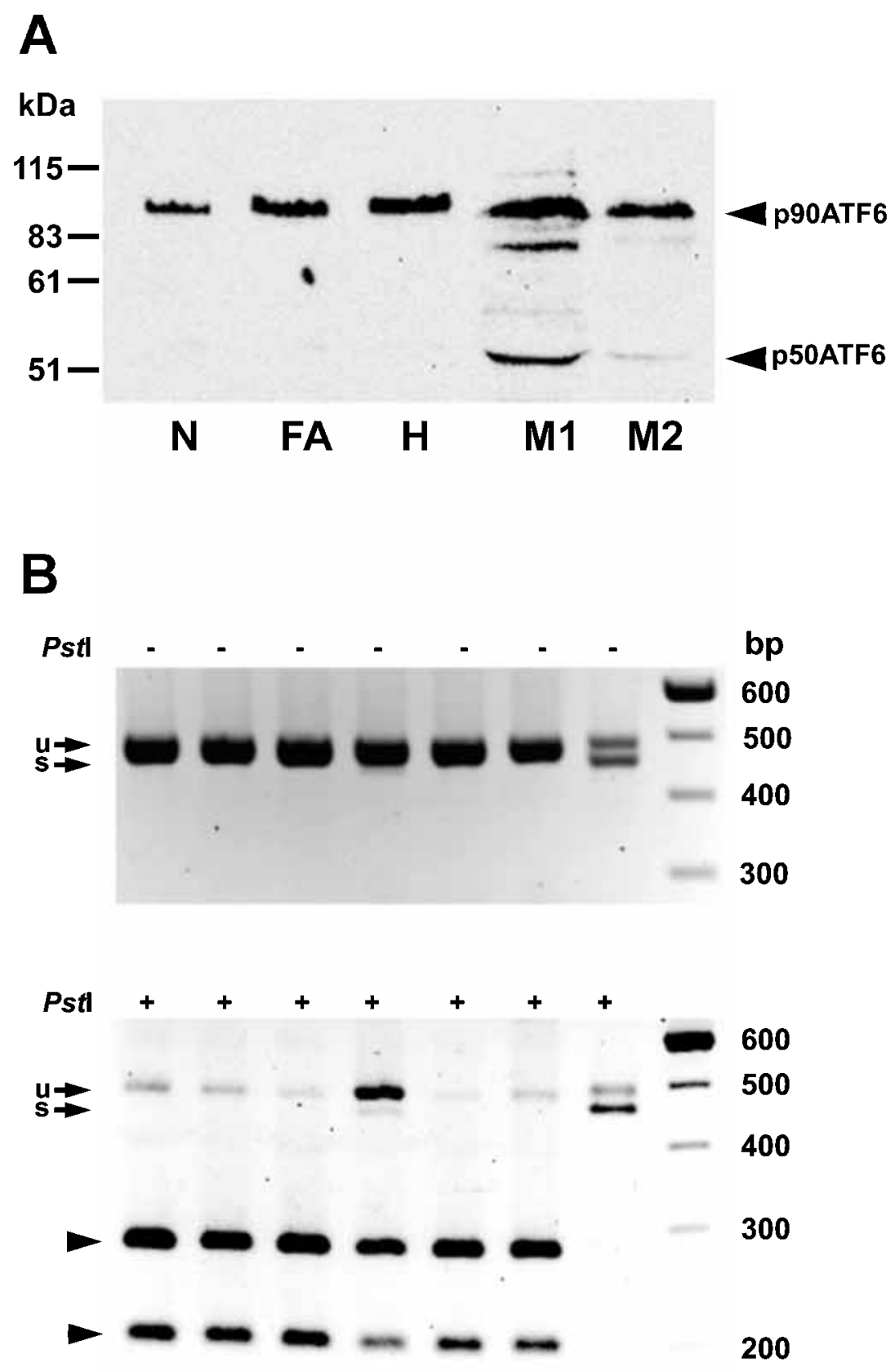

\section{$\begin{array}{lllllllll}N & \text { FA } & \text { H } & \text { M1 } & \text { M2 } & L & \text { Tun } & M\end{array}$}

Figure 7 ATF6 protein and XBP1 mRNA processing in the thyroids of affected patients. (A) Equal amounts of protein from the thyroid homogenates were analyzed by SDS-PAGE and Western blot using ATF6 $\alpha$ antibodies. Arrowheads indicate an $\sim 90 \mathrm{kDa}$ precursor (p90 ATF6) form of ATF6 and an $\sim 54 \mathrm{kDa}$ cleavage product (p50 ATF6). (B) Total RNA was isolated from thyroids and a $479 \mathrm{bp}$ fragment of XBP1 mRNA was amplified by RT-PCR. $\beta$-actin amplification was used as a loading control. Intact (upper panel) and Pstl-digested PCR fragments (lower panel) were separated on $2 \%$ agarose gel. Arrows indicate unspliced (u) and spliced (s) XBP1. Arrowheads indicate 281 and $198 \mathrm{bp}$ digestion products. XBP1 mRNA from human liver (lane L) and FRTL-5 rat thyroid cells treated with tunicamycin (lane Tun) were isolated, 479 bp XBP1 mRNA fragments were amplified by RT-PCR and digested by Pstl as indicated above. Lane M, DNA molecular weight ladder. N, thyroid tissue from the normal thyroid lobe (see Materials and methods), FA, follicular adenoma, H, Hashimoto's thyroiditis, M1, patient with a congenital hypothyroid goiter and C1264R Tg mutation and M2, patient with a variant type of adenomatous goiter and C1996S Tg mutation. 


\section{A}

\section{$\mathrm{kDa}$}

$115-$

\section{1 \\ $51-$}

$83-$

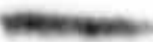

ง

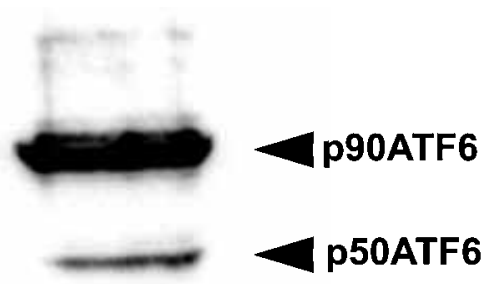

p50ATF6

\section{$+/+\quad+/ r d w \quad r d w / r d w$}

B
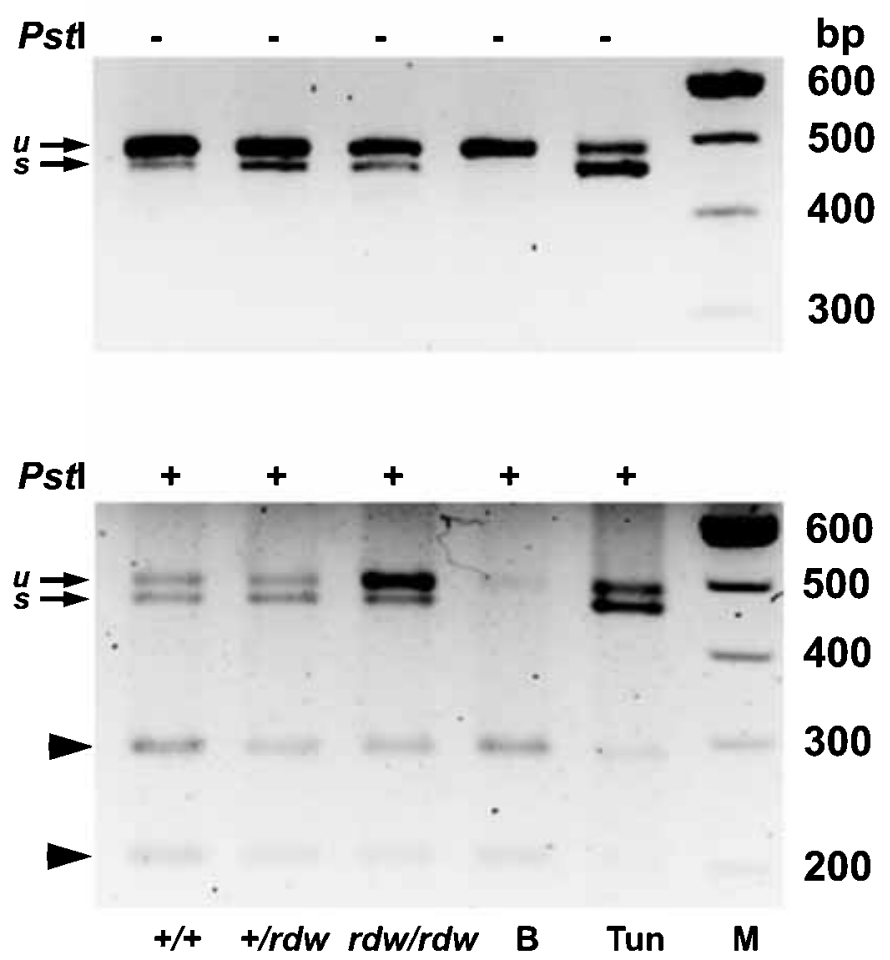

Figure 8 Activation of ATF6 and HTF in the $r d w$ rat thyroids. Thyroid homogenates from two animals in each group were pooled and equal amounts of protein were analyzed by SDS-PAGE and Western blot. (A) ATF6 processing in the thyroid tissues. Arrowheads indicate an $\sim 90 \mathrm{kDa}$ precursor (p90 ATF6) form of active ATF6 and an $\sim 54 \mathrm{kDa}$ cleavage product migrating to the nucleus as an active transcription factor (p50 ATF6). (B) Total RNA was isolated from the $r d w$ rat thyroids and a 485 bp fragment of HTF (XBP1) mRNA was amplified by RT-PCR. $\beta$-actin amplification was used as a loading control. Intact (upper panel) and Pstl-digested PCR fragments (lower panel) were separated on $2 \%$ agarose gel. Arrowheads indicate 287 and 198 bp digestion products. Arrows indicate unspliced (u) and spliced (s) HTF. XBP1 mRNA from rat brain (lane B) and FRTL-5 rat thyroid cells treated with tunicamycin (lane Tun) were isolated, 485 bp XBP1 mRNA fragments were amplified by RT-PCR and digested by $P s t l$ as indicated above. Lane M, DNA molecular weight ladder. 


\section{Discussion}

We have studied thyroid tissues from two unrelated patients with a congenital goiter and a variant type of adenomatous goiter, as well as thyroids from the rdw (dwarf) rats, which despite the absence of a goiter have a hypothyroid status similar to human subjects. Convincing evidence has suggested common molecular mechanisms underlying the development of the characteristic hypothyroid phenotype in human subjects and $r d w$ rats. In both cases, primary defects in thyroid hormonogenesis caused by the missense mutations in $\mathrm{Tg}$ were found to be responsible for the progression of disease. G1264R and C1996S mutations in the affected patients apparently disrupt the formation of important intramolecular disulfide bonds that stabilize the nascent $\mathrm{Tg}$ (Hishinuma et al. 1999). G2320R replacement in the highly conserved region of rat $\mathrm{Tg}$ in $r d w$ animals was suggested to cause structural instability of the molecule (Kim et al. 2000). The missense mutation in the same $\mathrm{Tg}$ domain observed in $\mathrm{cog} / \mathrm{cog}$ mice was hypothesized to have a negative impact on the homodimerization of $\mathrm{Tg}$ ( $\mathrm{Kim}$ et al. 1998b). Although the nature of the flawed folding step may vary, it is reasonable to assume that in all of the aforementioned cases the inability to form transport-competent $\mathrm{Tg}$ dimers resulted in the abnormal accumulation of $\mathrm{Tg}$ in the $\mathrm{ER}$ (Kim et al. 1998b). The ER retention of Tg was confirmed by its sensitivity to the treatment with endoglycosidase $\mathrm{H}$, the enzyme that digests only high mannose-type oligosaccharides associated with the ER-retained proteins (Hishinuma et al. 1999). However, despite the predicted overload of the ER with $\mathrm{Tg}$, the total tissue levels of the protein both in human and rat tissues were found to be drastically reduced (Figs 1 and 4). Several explanations might be considered. One might be that such a decrease occurs because of the augmented susceptibility of structurally destabilized Tg to proteolysis (Kim et al. 2000). However, we failed to detect immunoreactive proteolytic fragments (results not shown), although eventually secretion-incompetent $\mathrm{Tg}$ is probably eliminated by the ERAD. Another explanation is that, in normal thyroids, the total $\mathrm{Tg}$ pool is represented predominantly by follicular $\mathrm{Tg}$ as opposed to its intracellular stores and, therefore, the observed reduction might reflect the exhaustion of the extracellular $\mathrm{Tg}$, whereas the amounts of $\mathrm{Tg}$ in the ER may even increase. Indeed, this was indicated by reduced $\mathrm{Tg}$ immunoreactivity in the follicular lumen in the G1264R patient's thyroid tissue (Kim et al. 1996). In a similar case of congenital hypothyroid goiter, electron microscopy revealed a marked decrease of $\mathrm{Tg}$ in the follicular lumen whereas the intracellular pool was amplified (Medeiros-Neto et al. 1996). However, even these small amounts of $\mathrm{Tg}$ in the ER may not be detected by conventional SDS-PAGE as they frequently form aggregates that are unable to enter the resolving SDS gel. This was convincingly demonstrated in a study where native PAGE revealed high molecular weight $\mathrm{Tg}$ species in the thyroid extracts from the same patients (Hishinuma et al. 1999). PERK-mediated general translation attenuation was suggested as another possible explanation for the reduced level of $\mathrm{Tg}$ in $r d w$ rat thyroids (Kim et al. 2000). However, this signaling pathway is active only on the early stages of the UPR (Harding et al. 2002) and, as it is impossible to determine the kinetic phase of the UPR in the tissues studied, the contribution of this factor remains unclear.

Such an excessive accumulation of $\mathrm{Tg}$ in the ER with its further aggregation, abnormal distention of the ER and ensuing development of hypothyroid status represent a typical ERSD. Development of ERSDs is closely connected with ER quality control, the 'proof-reading' of newly synthesized proteins, so that only native conformers reach their final destinations (Ellgaard \& Helenius 2003). Quality control monitors not only the folding of single polypeptide chains but also the assembly of oligomers, such as Tg dimers and retain unassembled subunits in the ER with further degradation by the ERAD. However, as was shown for cystic fibrosis, another prototypic ERSD, a significant amount of the mutant transmembrane conductance regulator, entrapped in the ER, is still functional (Pasyk \& Foskett 1995). The same was shown for mutant $\mathrm{Tg}$ in the human patient with the G1264R mutation (Kim et al. 1996) and in $\operatorname{cog} / \operatorname{cog}$ mice (Kim et al. 1992), suggesting that the Tg defect is not severe enough to render the molecule absolutely useless for hormonogenesis. Therefore, the quality control may itself contribute to the disease pathogenesis by preventing the export of considerable fractions of functionally competent $\mathrm{Tg}$ molecules. For this reason, we have investigated the essential components of the quality control system, ER molecular chaperones and folding 
enzymes and, additionally, the key cytoplasmic and mitochondrial chaperones.

As expected, human tissues with G1264R and C1996S Tg variants contained significantly elevated amounts of practically all of the major ER chaperones. Comparable chaperone induction has been shown in a number of cases of congenital hypothyroid goiter connected with abnormalities in Tg trafficking (Kim et al. 1996, Medeiros-Neto et al. 1996). It was demonstrated that $\mathrm{BiP}$ and, to a lesser extent GRP94, are the major quality control factors that monitor the folding status of $\mathrm{Tg}$ by repetitive cycles of binding and dissociation (Kim et al. 1992, Kim \& Arvan 1995, Muresan \& Arvan 1997, 1998). Mutation of important cysteines in $\mathrm{Tg}$ presumably disrupts formation of correct disulfide bonds and thus prolongs the interaction of $\mathrm{BiP}$ and GRP94 with misfolded Tg.

Induction of other ER chaperones also reflects their participation in the maturation of $\mathrm{Tg}$. PDI and ERp72 are involved in the formation of the tertiary structure catalyzing the formation and rearrangement of disulfide bonds (Mazzarella et al. 1990, Noiva 1999). Calreticulin is an important member of the particular branch of ER quality control that surveys the folding of glycoproteins, such as $\mathrm{Tg}$ (Johnson et al. 2001). All of them were shown to associate with $\mathrm{Tg}$ in course of its folding (Kuznetsov et al. 1994, Nigam et al. 1994, Muresan \& Arvan 1998). In addition to known folding factors and enzymes whose role in protein maturation is relatively well characterized we have also studied a novel ER factor with a not well-defined function, ERp29, which was recently shown to associate with $\mathrm{Tg}$ along with $\mathrm{BiP}$ and GRP94 in cultured rat thyrocytes upon their stimulation with thyrotropin (Mkrtchian et al. 1998, Sargsyan et al. 2002). Significant association with $\mathrm{Tg}$ in human mutant tissues (Fig. 3B) and its upregulation corroborate previous observations and lend more support to the important role of ERp29 in the folding/secretion of Tg. However, its physiological function probably differs from the straight chaperoning similar to $\mathrm{BiP}$ or GRP94 function as it may interact even with completely folded $\mathrm{Tg}$ unlike $\mathrm{BiP}$ which binds exclusively to misfolded or nascent proteins (Sargsyan et al. 2002). Although the N-terminal domain of ERp29 is a structural analogue of the thioredoxin domain of PDI, the absence of a characteristic double cysteine active center rules out its PDI/ERp72-like redox activity (Liepinsh et al. 2001). However, the discovery of ERp29 secretion despite its C-terminal ER retrieval signal suggests an interesting functional role for ERp29, a putative $\mathrm{Tg}$ escort chaperone (Sargsyan et al. 2002). This hypothesis is currently under scrutiny in our laboratory.

In general, the expression of chaperones is substantially stronger in mutant human tissues than in $r d w$ rats. Perhaps a critical role here is the different mode of $\mathrm{Tg}$ accumulation in the ER. Aggregation of $\mathrm{Tg}$ in mutant human tissues might prevent or at least substantially complicate elimination of defective $\mathrm{Tg}$ molecules via ERAD, thus augmenting the UPR (Hishinuma et al. 1999). On the contrary, the intracellular $\mathrm{Tg}$ pool in the mutant rats was found to be rather heterogeneous with the partial formation of monomers (Kim et al. 2000). The absence of $\mathrm{Tg}$ multimers may allow rapid processing of the mutant $\mathrm{Tg}$ by the ERAD and, thus, reduce the UPR signaling reflected in the substantially lower fold inductions of chaperones.

Induction of cytoplasmic and mitochondrial chaperones in the affected patients is another interesting phenomenon that has not been observed before. The magnitude of the ER reorganization upon massive accumulation of secretion-incompetent $\mathrm{Tg}$ aggregates apparently invokes not only ER specific but also general cellular cytoprotective mechanisms, of which cytoplasmic and mitochondrial chaperones are the important part. The extent of the mtHSP70 induction is very strong and comparable with the expression of BiP and GRP94, indicating its essential role in maintaining cell homeostasis. mtHSP70 has multiple functions but most importantly it is indispensable for mitochondrial biogenesis and protein import, which predictably affect the essential mitochondrial functions, such as supply of energy, regulation of calcium levels and control of apoptosis (Kaul et al. 2002). This implies that mtHSP70 may indirectly support increased demands for the biosynthesis of ATP-dependent ER chaperones (BiP and GRP94) or other functions of stressed ER dependent on metabolic energy sources. A recent study on the transmission of ER stress to mitochondria supports this notion, demonstrating induction of mtHSP70 and other mitochondrial chaperones in the ER-stressed HeLa cells (Hori et al. 2002). Interestingly, as seen in Fig. 2, mtHSP70 was also strongly upregulated in 
the thyroid from the patient with Hashimoto's disease. The reason for such activation is somewhat obscure. It was demonstrated that the thyrocytes from patients with Hashimoto's thyroiditis are destroyed as a result of an apoptotic process. Given the established role of mitochondria in the development of apoptosis, it is tempting to speculate about the putative role of mtHSP70 in the disease pathogenesis. Obviously, it would require further studies to substantiate this hypothesis.

Co-ordinated induction of the ER and cytoplasmic (HSP70 and HSP90) chaperones may have different explanations. HSP70 and HSP90 are actively involved in intracellular protein trafficking, assisting in the transport of the ER and mitochondrial proteins through the corresponding translocation channels. It was shown, for instance, that both these chaperones facilitate interaction between the apoprotein B molecules destined for degradation and the components of the proteasomal machinery (Fisher et al. 1997, Gusarova et al. 2001). Presumably, augmented flow of the mutant $\mathrm{Tg}$ to the proteasomes may require increased amounts of cytosolic factors aiding in its proteasomal targeting. HSP90 may have more specific, UPR-related functions, as it was found to stabilize the cytoplasmic domain of IRE1 and, thus, can augment the ER stress response (Marcu et al. 2002). These data demonstrate that chaperone systems on both sides of the ER membrane serve to integrate this signal transduction pathway. In general, the transcriptional scope of the UPR is remarkably broad. Originally thought to be confined only to the induction of ER chaperones, it is currently suggested to affect virtually every step of the secretory pathway and beyond. For instance, recent genome-wide expression analysis in yeast revealed nearly 400 genes upregulated in the course of ER stress (Travers et al. 2000).

The mechanisms of UPR are well studied under the stress conditions triggered by the inhibitions of glycosylation, $\mathrm{Ca}^{2+}$ depletion and other impacts that interfere with protein folding in the ER. However, the information on the transcriptional regulation of UPR target genes in the etiopathogenesis of ERSDs is limited. Our data provided evidence for the differential activation of the major UPR transducers, ATF6 and XBP1, in a typical ERSD, human and rat variants of the thyroid disorder connected with abnormal $\mathrm{Tg}$ transport.
Similarly to the variety of the ER stress models, upregulation of the transcriptional branch of UPR in the human and rat tissue studies basically correlates with the expression of ER rescue proteins. However, there are some important and unexpected distinctions between the activation of ATF6 and XBP1 in different species.

Thus, whereas ATF6 cleavage and, to a lesser extent, splicing of XBP1 mRNA seem to parallel the increased chaperone expression in both mutant human tissues, in rat thyroids chaperone induction in heterozygote animals was not accompanied by ATF6 activation. The reason for such a discrepancy is not clear. It might be speculated that the anti-human ATF6 antibodies are not specific enough to detect small amounts of the protein in the $+/ r d w$ rat thyroids. A less likely possibility is that an as yet unknown signaling cascade induces chaperones in $+/ r d w$ rats.

Another interesting observation indicating the different mode of activation of IRE1/XBP1 and ATF6 is the surprisingly high level of processed XBP1 mRNA in all of the rat thyroid tissues. Although the amount of spliced mRNA seemed to increase from the wild-type to $r d w / r d w$ rats (Fig. 8B), indicating further activation of IRE1 kinase/endonuclease, still the wild-type thyroid contained rather high amounts of the spliced product. Such a situation is inconsistent with the previously proposed model of XBP1 processing, according to which in quiescent cells XBP1 mRNA is represented predominantly by the unspliced form that is induced by ATF6 and spliced by IRE1 under ER stress conditions. However, this model is based mostly on studies in cultured cells, whereas the situation in vivo is much less clear. Opposite to the yeast cells where the IRE1 signaling is the central regulatory switch of the UPR, in the mammalian cells UPR is regulated by several signaling pathways, the relative importance of which, under physiological and pathological conditions, is yet not fully understood. The ATF6 pathway apparently plays a central role in the stress-induced transcriptional upregulation of immediate rescue genes, chaperones, whereas IRE1/XBP1 may also target genes that control the basic secretory function of the ER and beyond (Calfon et al. 2002, Iwakoshi et al. 2003). Thus, XBP1 is essential for plasma cell differentiation, especially during transition into the antibodysecreting cells (Reimold et al. 2000, Gass et al. 2002, 
Iwakoshi et al. 2003). Presumably, the level of spliced, active XBP1 mRNA might be specifically high in the professional secretory tissues, such as plasma cells and thyroid, and substantially lower in other tissues. Strong PstI sensitivity of the XBP1 mRNA from the normal brain and liver is consistent with this suggestion (Figs $7 \mathrm{~B}$ and $8 \mathrm{~B}$ ). Very low levels of spliced XBP1 in the different parts of normal brain have also been reported by other groups (Kumar et al. 2003, Paschen et al. 2003).

The above-discussed data, although providing some interesting insights into XBP1 processing in different tissues, still cannot answer all the questions, such as, for instance, the diverse regulation of XBP1 in human and rat thyroid tissues, substantiating the need for further studies on this subject.

In conclusion, we have extended our previous observations of ER chaperone induction under Tg-related ERSDs with the identification of the additional ER (ERp29, ERp72, calreticulin, PDI), cytoplasmic (HSP70, HSP90) and mitochondrial (mtHSP70) chaperones and folding enzymes apparently involved in the molecular pathology of the disorder studied. Moreover, BiP and ERp29 were found to be associated with $\mathrm{Tg}$ in the mutant human and rat tissue, suggesting the important role of the quality control machinery in the retention of misfolded $\mathrm{Tg}$ in the ER. Upregulation of ER chaperones under these conditions is apparently initiated through the activation of the major UPR transducers, XBP1 (HTF) and p50ATF6 $\alpha$, which would suggest the immediate involvement of UPR in the molecular pathogenesis of hypothyroid ERSDs.

\section{Acknowledgements}

We thank Dr L Hendershot and Dr L Meunier for the polyclonal anti-mouse BiP, Dr L Gorza for anti-GRP94, Dr B Di Jeso for anti-rat Tg, Dr J C Higuita for anti-ERp72 and anti-calreticulin and Dr K Mori for anti-ATF6 and anti-XBP1. We are grateful to Professor M Ingelman-Sundberg (Molecular Toxicology, IEM, Karolinska Institute) for his constant support and encouragement.

This work was supported by the Swedish Medical Research Council and Swedish Society for Medical Research (S M). M B and E S received scholarships from the Royal Swedish Academy, Swedish Institute and the Swedish Foundation for International Cooperation in Research and Higher Education. A H was supported by a grant from the Japan Society for the Promotion of Science. S F was supported by a High-tech Research Center grant from the Ministry of Education, Science and Culture of Japan and the Foundation for Growth Science.

\section{References}

Aridor M \& Balch WE 1999 Integration of endoplasmic reticulum signaling in health and disease. Nature Medicine 5 745-751.

Bertolotti A, Zhang Y, Hendershot LM, Harding HP \& Ron D 2000 Dynamic interaction of $\mathrm{BiP}$ and ER stress transducers in the unfolded-protein response. Nature Cell Biology 2 326-332.

Calfon M, Zeng H, Urano F, Till JH, Hubbard SR, Harding HP, Clark SG \& Ron D 2002 IRE1 couples endoplasmic reticulum load to secretory capacity by processing the XBP-1 mRNA. Nature 415 92-96.

Chomczynski P \& Sacchi N 1987 Single-step method of RNA isolation by acid guanidinium thiocyanate-phenol-chloroform extraction. Annals of Biochemistry 162 156-159.

Ellgaard L \& Helenius A 2003 Quality control in the endoplasmic reticulum. Nature Reviews Molecular Cell Biology 4 181-191.

Fisher EA, Zhou M, Mitchell DM, Wu X, Omura S, Wang H, Goldberg AL \& Ginsberg HN 1997 The degradation of apolipoprotein $\mathrm{B} 100$ is mediated by the ubiquitin-proteasome pathway and involves heat shock protein 70. Fournal of Biological Chemistry 272 20427-20434.

Gass JN, Gifford NM \& Brewer JW 2002 Activation of an unfolded protein response during differentiation of antibody-secreting B cells. Fournal of Biological Chemistry 277 49047-49054.

Gething MJ 1999 Role and regulation of the ER chaperone BiP. Seminars in Cell Development Biology 10 465-472.

Gusarova V, Caplan AJ, Brodsky JL \& Fisher EA 2001 Apoprotein $\mathrm{B}$ degradation is promoted by the molecular chaperones hsp90 and hsp70. Fournal of Biological Chemistry 276 24891-24900.

Hampton RY 2002 ER-associated degradation in protein quality control and cellular regulation. Current Opinion in Cell Biology 14 476-482.

Harding HP, Zhang Y \& Ron D 1999 Protein translation and folding are coupled by an endoplasmic-reticulum-resident kinase. Nature 397 271-274.

Harding HP, Galfon M, Urano F, Novoa I \& Ron D 2002 Transcriptional and translational control in the Mammalian unfolded protein response. Annual Reviewes in Cell Development Biology 18 575-599.

Haze K, Yoshida H, Yanagi H, Yura T \& Mori K 1999 Mammalian transcription factor ATF6 is synthesized as a transmembrane protein and activated by proteolysis in response to endoplasmic reticulum stress. Molecular Biology of the Cell $\mathbf{1 0}$ 3787-3799.

Haze K, Okada T, Yoshida H, Yanagi H, Yura T, Negishi M \& Mori K 2001 Identification of the G13

(cAMP-response-element-binding protein-related protein) gene product related to activating transcription factor 6 as a transcriptional activator of the mammalian unfolded protein response. Biochemical fournal 355 19-28.

Hishinuma A, Kasai K, Masawa N, Kanno Y, Arimura M, Shimoda SI \& Ieiri T 1998 Missense mutation (C1263R) in the thyroglobulin gene causes congenital goiter with mild 
hypothyroidism by impaired intracellular transport. Endocrine fournal 45 315-327.

Hishinuma A, Takamatsu J, Ohyama Y, Yokozawa T, Kanno Y, Kuma K, Yoshida S, Matsuura N \& Ieiri T 1999 Two novel cysteine substitutions (C1263R and C1995S) of thyroglobulin cause a defect in intracellular transport of thyroglobulin in patients with congenital goiter and the variant type of adenomatous goiter. Fournal of Clinical Endocrinology and Metabolism 84 1438-1444.

Hishinuma A, Furudate S, Oh-Ishi M, Nagakubo N, Namatame T \& Ieiri T 2000 A novel missense mutation (G2320R) in thyroglobulin causes hypothyroidism in rdw rats. Endocrinology 141 4050-4055.

Hori O, Ichinoda F, Tamatani T, Yamaguchi A, Sato N, Ozawa K, Kitao Y, Miyazaki M, Harding HP, Ron D et al. 2002

Transmission of cell stress from endoplasmic reticulum to mitochondria: enhanced expression of Lon protease. Fournal of Cell Biology 157 1151-1160.

Iwakoshi NN, Lee AH, Vallabhajosyula P, Otipoby KL, Rajewsky K \& Glimcher LH 2003 Plasma cell differentiation and the unfolded protein response intersect at the transcription factor XBP-1. Nature Immunology 4 321-329.

Johnson S, Michalak M, Opas M \& Eggleton P 2001 The ins and outs of calreticulin: from the ER lumen to the extracellular space. Trends in Cell Biology 11 122-129.

Kaufman RJ 2002 Orchestrating the unfolded protein response in health and disease. Fournal of Clinical Investigation 110 1389-1398.

Kaul SC, Taira K, Pereira-Smith OM \& Wadhwa R 2002 Mortalin: present and prospective. Experimental Gerontology 37 1157-1164.

Kim PS \& Arvan P 1995 Calnexin and BiP act as sequential molecular chaperones during thyroglobulin folding in the endoplasmic reticulum. Fournal of Cell Biology 128 29-38.

Kim PS \& Arvan P 1998a Endocrinopathies in the family of endoplasmic reticulum (ER) storage diseases: disorders of protein trafficking and the role of ER molecular chaperones. Endocrine Reviewes 19 173-202.

Kim PS, Bole D \& Arvan P 1992 Transient aggregation of nascent thyroglobulin in the endoplasmic reticulum: relationship to the molecular chaperone, BiP. Fournal of Cell Biology 118 541-549.

Kim PS, Kwon OY \& Arvan P 1996 An endoplasmic reticulum storage disease causing congenital goiter with hypothyroidism. Journal of Cell Biology 133 517-527.

Kim PS, Hossain SA, Park YN, Lee I, Yoo SE \& Arvan P 1998 b A single amino acid change in the acetylcholinesterase-like domain of thyroglobulin causes congenital goiter with hypothyroidism in the $\operatorname{cog} / \operatorname{cog}$ mouse: a model of human endoplasmic reticulum storage diseases. PNAS 95 9909-9913.

Kim PS, Ding M, Menon S, Jung CG, Cheng JM, Miyamoto T, Li B, Furudate S \& Agui T 2000 A missense mutation G2320R in the thyroglobulin gene causes non-goitrous congenital primary hypothyroidism in the WIC-rdw rat. Molecular Endocrinology 14 1944-1953.

Koto M, Sato T, Okamoto M \& Adachi J 1988 rdw rats, a new hereditary dwarf model in the rat. Fikken Dobutsu 37 21-30.

Kumar R, Krause GS, Yoshida H, Mori K \& DeGracia DJ 2003 Dysfunction of the unfolded protein response during global brain ischemia and reperfusion. Journal of Cerebellum Blood Flow Metabolism 23 462-471.

Kuznetsov G, Chen LB \& Nigam SK 1994 Several endoplasmic reticulum stress proteins, including ERp72, interact with thyroglobulin during its maturation. Fournal of Biological Chemistry 269 22990-22995.

Lee K, Tirasophon W, Shen X, Michalak M, Prywes R, Okada T, Yoshida H, Mori K \& Kaufman RJ 2002 IRE1-mediated unconventional mRNA splicing and S2P-mediated ATF6 cleavage merge to regulate $\mathrm{XBP} 1$ in signaling the unfolded protein response. Genes and Development $16452-466$.
Liepinsh E, Baryshev M, Sharipo A, Ingelman-Sundberg M, Otting G \& Mkrtchian S 2001 Thioredoxin fold as homodimerization module in the putative chaperone ERp29. NMR structures of the domains and experimental model of the $51 \mathrm{kDa}$ dimer. Structure 9 $457-471$.

Lowry OH, Rosebrough NJ, Farr AL \& Randall RJ 1952 Protein measurements with the Folin phenol reagent. Fournal of Biological Chemistry 193 265-275.

Marcu MG, Doyle M, Bertolotti A, Ron D, Hendershot L \& Neckers L 2002 Heat shock protein 90 modulates the unfolded protein response by stabilizing IRE1 alpha. Molecular and Cellular Biology 22 8506-8513.

Mazzarella RA, Srinivasan M, Haugejorden SM \& Green M 1990 ERp72, an abundant luminal endoplasmic reticulum protein, contains three copies of the active site sequences of protein disulfide isomerase. Fournal of Biological Chemistry 265 1094-1101.

Medeiros-Neto G, Kim PS, Yoo SE, Vono J, Targovnik HM, Camargo R, Hossain SA \& Arvan P 1996 Congenital hypothyroid goiter with deficient thyroglobulin. Identification of an endoplasmic reticulum storage disease with induction of molecular chaperones. Fournal of Clinical Investigation 98 2838-2844.

Mkrtchian S, Fang C, Hellman U \& Ingelman-Sundberg M 1998 A stress-inducible rat liver endoplasmic reticulum protein, ERp29. European Fournal of Biochemistry $251304-313$.

Mori K 2000 Tripartite management of unfolded proteins in the endoplasmic reticulum. Cell 101 451-454.

Muresan Z \& Arvan P 1997 Thyroglobulin transport along the secretory pathway. Investigation of the role of molecular chaperone, GRP94, in protein export from the endoplasmic reticulum. Fournal of Biological Chemistry 272 26095-26102.

Muresan Z \& Arvan P 1998 Enhanced binding to the molecular chaperone BiP slows thyroglobulin export from the endoplasmic reticulum. Molecular Endocrinology 12 458-467.

Nigam SK, Goldberg AL, Ho S, Rohde MF, Bush KT \& Sherman M 1994 A set of endoplasmic reticulum proteins possessing properties of molecular chaperones includes $\mathrm{Ca}(2+)$-binding proteins and members of the thioredoxin superfamily. Fournal of Biological Chemistry 269 1744-1749.

Noiva R 1999 Protein disulfide isomerase: the multifunctional redox chaperone of the endoplasmic reticulum. Seminars in Cell Development Biology 10 481-493.

Nyfeler B, Nufer O, Matsui T, Mori K \& Hauri HP 2003 The cargo receptor ERGIC-53 is a target of the unfolded protein response. Biochemical and Biophysical Research Communications 304 599-604.

Oh-Ishi M, Omori A, Kwon JY, Agui T, Maeda T \& Furudate SI 1998 Detection and identification of proteins related to the hereditary dwarfism of the rdw rat. Endocrinology 139 1288-1299.

Paschen W, Aufenberg C, Hotop S \& Mengesdorf T 2003 Transient cerebral ischemia activates processing of xbpl messenger RNA indicative of endoplasmic reticulum stress. Fournal of Cerebellum Blood Flow Metabolism 23 449-461.

Pasyk EA \& Foskett JK 1995 Mutant (delta F508) cystic fibrosis transmembrane conductance regulator Cl- channel is functional when retained in endoplasmic reticulum of mammalian cells. Journal of Biological Chemistry 270 12347-12350.

Plemper RK \& Wolf DH 1999 Retrograde protein translocation: eradication of secretory proteins in health and disease. Trends in Biochemical Science 24 266-270.

Reimold AM, Etkin A, Clauss I, Perkins A, Friend DS, Zhang J, Horton HF, Scott A, Orkin SH, Byrne MC et al. 2000 An essential role in liver development for transcription factor XBP-1. Genes and Development 14 152-157.

Rutishauser J \& Spiess M 2002 Endoplasmic reticulum storage diseases. Swiss Medical Weekly 132 211-222. 
Sargsyan E, Baryshev M, Szekely L, Sharipo A \& Mkrtchian S 2002 Identification of ERp29, an endoplasmic reticulum lumenal protein, as a new member of the thyroglobulin folding complex. Fournal of Biological Chemistry 277 17009-17015.

Shen J, Chen X, Hendershot L \& Prywes R 2002 ER stress regulation of ATF6 localization by dissociation of BiP/GRP78 binding and unmasking of Golgi localization signals. Developmental Cell 3 99-111.

Shen X, Ellis RE, Lee K, Liu CY, Yang K, Solomon A, Yoshida H, Morimoto R, Kurnit DM, Mori K et al. 2001 Complementary signaling pathways regulate the unfolded protein response and are required for C. elegans development. Cell 107 893-903.

Tirasophon W, Welihinda AA \& Kaufman RJ 1998 A stress response pathway from the endoplasmic reticulum to the nucleus requires a novel bifunctional protein kinase/endoribonuclease (Irelp) in mammalian cells. Genes and Development 12 1812-1824.

Travers KJ, Patil CK, Wodicka L, Lockhart DJ, Weissman JS \& Walter P 2000 Functional and genomic analyses reveal an essential coordination between the unfolded protein response and ER-associated degradation. Cell 101 249-258.
Wang XZ, Harding HP, Zhang Y, Jolicoeur EM, Kuroda M \& Ron D 1998 Cloning of mammalian Irel reveals diversity in the ER stress responses. Embo fournal 17 5708-5717.

Yoshida H, Haze K, Yanagi H, Yura T \& Mori K 1998 Identification of the cis-acting endoplasmic reticulum stress response element responsible for transcriptional induction of mammalian glucose-regulated proteins. Involvement of basic leucine zipper transcription factors. Fournal of Biological Chemistry 273 33741-33749.

Yoshida H, Matsui T, Yamamoto A, Okada T \& Mori K 2001 XBP1 mRNA is induced by ATF6 and spliced by IRE1 in response to ER stress to produce a highly active transcription factor. Cell 107 881-891.

Yoshida H, Matsui T, Hosokawa N, Kaufman RJ, Nagata K \& Mori K 2003 A time-dependent phase shift in the mammalian unfolded protein response. Developmental Cell 4 265-271.

Received 27 October 2003

Accepted 17 February 2004 